\title{
DERLEME
}

\section{İnfertilite ve Hemşirelik Yaklaşımı}

\section{$\ddot{O Z Z}$}

\author{
Elif ÖZDEMIR ${ }^{1}$, Sena KAPLAN ${ }^{2}$
}

Pek çok toplumda evliliğin amaçlarından biri de çocuk sahibi olmak olarak algılandığ için, üreme kültürel, sosyal ve psikolojik yönden bir gereksinimdir. İnfertilite toplumsal bir sağlık sorunu olmakla birlikte, çiftleri ve özellikle kadınları biyolojik, fiziksel ve psikososyal yönden olumsuz etkileyen bir durumdur. Aynı zamanda infertiliteye yönelik uygulanan tedaviler çiftler için psikolojik yönden zorlayıcı, duygusal yönden oldukça stresli, ekonomik anlamda pahalı olmakla birlikte eş ilişkilerini de olumsuz etkileyebilen bir kriz durumudur. İnfertilite kliniğinde çalışan hemşirelerin infertilite tedavisi süresince çiftlerle birebir iletişimde oldukları için yaşanabilecek sorunları erken dönemde belirlemesi ve uygun hemşirelik yaklaşımını planlayarak çiftlere destek olması önem taşımaktadır. İnfertilite hemşiresinin verebileceği danışmalık, eğitim ve sosyal destek ile kriz anında oluşabilecek olumsuz etkiler azaltılabilmektedir. Bu derleme çalışmasında infertilitenin çiftler üzerine etkisinin literatür kapsamında incelenmesi ve infertilite hemşiresinin rolüne vurgu yapılması amaçlanmıştır.

Anahtar Kelimeler: Hemşire; İnfertilite; Psikososyal yönü

\section{Infertility and Nursing Approach \\ Elif ÖZDEMIR', Sena KAPLAN ${ }^{2}$}

\begin{abstract}
Since one of the aims of marriage in many societies is perceived as having children, fertility is a cultural, social and psychological requirement. While infertility is a social health issue, it is also a condition that affects couples and especially women negatively in biological, physical and psychosocial aspects. At the same time, the treatments for infertility are crisis situations that are both psychologically challenging, emotionally stressful, economically expensive and that have negative effects on the relationships of couples. Since nurses working in the infertility clinic are in direct contact with the couples during the infertility treatment, it is important that they identify possible problems earlier and support the couples by planning the appropriate nursing approach. With the counseling, training and social support that the infertility nurse can provide, the negative effects that may occur in time of crisis can be reduced. In this compilation study, it is aimed to examine the effect of infertility on couples within the scope of the literature and to emphasize the role of infertility nurse.
\end{abstract}

Keywords: Infertility; Nursing; Psychosocial aspect

${ }^{1}$ Ankara Üniversitesi İbni Sina Araştırma ve Uygulama Hastanesi, Ankara, Türkiye.

${ }^{2}$ Ankara Yıldırım Beyazıt Üniversitesi Sağlık Bilimleri Fakültesi, Hemşirelik Bölümü, Ankara, Türkiye. Sorumlu Yazar: Sena KAPLAN

E-posta adresi: ataykaplan@yahoo.com

ORCID No: 0000-0002-1677-5463

Gönderi Tarihi: 05.12.2020

Kabul Tarihi: 08.12.2020 


\section{GíRiș}

Üreme bir canlının soyunu sürmesi olayıdır. İnfertilite, kadın ya da erkek kaynaklı sorun ya da sorunlar nedeniyle üreme olayının olmamasıdır $(1,2)$. Dünya Sağlık Örgütü (DSÖ)'ne göre (3) infertilite; korunmasız, düzenli cinsel ilişki olmasına rağmen 12 ay veya daha fazla süre klinik bir gebelik oluşmaması olarak tanımlanmaktadır. Pek çok toplumda evliliğin amaçlarından biri de çocuk sahibi olmak olarak algılandığı için, üreme kültürel, sosyal ve psikolojik yönden bir gereksinimdir (4). Bu bakımdan infertilite sorunu yaşayan birçok evli çift toplum tarafından psikososyal yönden baskı hissetmektedir (5). Soyunu devam ettirememe ve üreme yeteneğinin olmamas 1 infertil çiftlerde yetersizlik duygusu yaşamalarına neden olmaktadır (6). Yapılan çalışmalar da infertil çiftlerde ileri dönemde kayg1 bozukluğu, depresyon, cinsel sorunlar, toplumsal izolasyon, benlik saygısında azalma, evlilik uyumunda bozulma gibi sorunların fertil çiftlere göre daha fazla görüldüğünü göstermektedir $(7,8)$.

$\mathrm{Bu}$ derleme çalışmasında infertilitenin çiftler üzerine etkisinin literatür kapsamında incelenmesi ve infertilite hemşiresinin rolüne vurgu yapılması amaçlanmıştır.

\section{İnfertilite Tanımı ve Epidemiyolojisi}

İnfertilite DSÖ (3) tarafından; korunmasız, düzenli cinsel ilişki bulunmasına rağmen 12 ay veya daha fazla süre ile klinik olarak bir gebelik oluşmaması olarak tanımlanmaktadır. İnfertilite primer ve sekonder infertilite olarak ikiye ayrılmakta olup, primer infertilite en az bir yıl korunmasız cinsel ilişkiye rağmen gebeliğin olmaması, sekonder infertilite ise daha önce gebeliğin olmasına rağmen son bir yıl içerisinde korunmasız cinsel ilişkide bulunup gebe kalınamaması olarak tanımlanmaktadır (9).

İnfertilite, global olarak toplumsal bir sağlık sorunu olduğu kabul edilmekle birlikte üreme döneminde olan çiftleri $\% 9$ ila $\% 30$ arasında etkilemektedir (10). DSÖ, dünyadaki infertil çiftlerin 60-80 milyon olduğunu bildirmektedir (11). İnfertilitenin görülme sıklığı, dünyada ülkeler arasında değişmekle beraber bölgeden bölgeye de değişiklik göstermektedir. Verilere göre, gelişmekte olan ülkelerde infertilite insidansının gelişmiş ülkelere göre daha yüksek oranda olduğu belirtilmektedir (12). Yapılan epidemiyolojik araştırmalar incelendiğinde; infertilite yaygınlığının özellikle Orta Doğu Avrupa, Güney Asya, Orta Asya ve Kuzey Afrika da oldukça yüksek düzeyde olduğu 
saptanmıştır $(13,14)$. İnfertilite prevalansını belirtmek üzere Felice ve ark. (10) tarafindan yapılan bir uluslararası araştırmada infertilite oranının Amerika'da \%15, Avrupa'da \%15, Doğu Afrika'da \%27, Orta Asya'da \%17 olduğu belirlenmiştir. Bunun yanı sıra İngiltere'de yedi çiftten birinin infertilite tanısı almaktadır (15). Ülkemizde ise, 1.5 - 2 milyon infertil çift olduğu bildirmektedir (16). Türkiye Nüfus ve Sağlık Araştırması (TNSA) 2013 ve 2018 y1lı (50) verilerine göre, 15-49 yaş arasında hiç çocuğu olmayan ve çocuk sahibi olmasının mümkün olmadığını belirten evli kadınların oranı \%4'dür. Bunun yanı sıra aynı çalışmada doğum sonrası en az bir kez infertilite sorunu yaşayanların oranının 2013 yılında $\% 11.2 ; 2018$ y1lında ise $\% 12$ olduğu belirtilmektedir (17).

\section{İnfertilite Nedenleri}

Fertil olan çiftlerde gebelikten korunmaya yönelik bir yöntem kullanımı bulunmadığında, gebe kalma ihtimali her ovulatuvar siklusta ortalama \%20'dir (18). İnfertilite ise düzenli cinsel ilişki bulunmasına rağmen, 12 ay ve üzerindeki sürede gebeliğin olmamasıdır (19). İnfertilitede $\% 40$ ila $\% 50$ oranında kadına bağlı faktörler, $\% 30$ ila $\% 40$ oranında ise erkeğe bağlı faktörlerle fertilizasyonun oluşmamaktadır. Açıklanamayan infertiliteye bağlı faktörler ise \%15 oranında etkili olmaktadır (18). Bunun yanı sıra fiziksel, sosyoekonomik, psikososyal ve çevresel değişkenlere bağlı nedenler de fertiliteyi önemli ölçüde olumsuz etkilemektedir (20).

Literatür incelendiğinde infertiliteye neden olan kadın kaynaklı faktörlerin, ileri yaş, ilişki sıklığı, zamanlaması, sigara ve alkol- kullanımı, ağır egzersiz ve kilo değişimleri, aşırı strese maruz kalma, yetersiz beslenme, diyabet, hipertansiyon, astım gibi kronik hastalıkların, çevresel ya da mesleğe ait kurşun, civa, arsenik, radyasyon gibi toksik maddelere maruz kalma, antidepresan ve antihipertansif gibi ilaçların düzenli kullanımı ve cinsel yolla bulaşan hastalıklar olduğu belirtilmektedir (20,21). Yapılan çalışmalarda, kadının yaşı ilerledikçe infertilite oranının da arttığı belirtilmiştir (22). Diğer bir çalışmada ise obezite sorunu yaşayan kadınlar, beden kitle indeksi $30 \mathrm{~kg} / \mathrm{m}^{2}$ 'nin altında olan kadınlarla karşılaştırıldığında gebe kalma süreçlerinin uzadığı belirlenmiştir (23). Bununla birlikte stres faktörü hem kadın hem de erkekte cinsel ilişki sıklığı ve lipidonun azalmasına neden olup, infertiliye neden olduğu belirlenmiştir (24). Amerika'da yapılan bir 
araştırmada, korunmasız ve düzenli cinsel ilişkide bulunan çiftlerde ileri yaşın, sigara ve alkol kullanımının, yetersiz beslenmenin, cinsel yolla bulaşan hastalıkların infertiliteyi etkileyen faktörler arasında olduğu belirlenmiştir (25).

Aynı zamanda kadınlarda infertiliteye neden olan diğer faktörler; konjenital gelişimsel faktörler, anovulasyon, polikistik over sedromu, luteal faz yetmezliği gibi overian sorunlar, uterusa ve servikse ilişkin faktörler, tubal ve peritoneal faktörler, vulva ve vajene ait faktörlerdir (26). Polanya'da yapılan bir çalışmada (27), kadınlarda infertiliteye neden olan faktörler arasında; uterusun yapısal anomalilerinin $\% 7.3, \quad$ ovulasyon bozukluklarının \%54.4, idiyopatik infertilitenin $\% 22.3$, endometriosizin $\% 4.4$, polikistik over sendromunun $\% 19.9$, tubal tıkanıklıkların $\% 16.5$ rol oynadığı belirlenmiştir.

İnfertiliteye neden olan erkek kaynaklı faktörler ise varikosel, kliptorşidizm, hipospadias, düşük testesteron seviyesi, orşit gibi yapısal ve hormonal bozukluklar, spermin yapısındaki değişiklikler, sperm sayısının ve libidonun azaldığı durumlar, ereksiyon bozukluklarıdır. Ayrıca diğer faktörler ise stres, iş yerinde radyasyon ya da kurşun, civa, x-ray gibi toksik maddelere maruz kalma, skrotumun yüksek 1sıya maruz kalmadır $(26,53)$. Yapılan çalışmalarda erkek infertilite nedenleri arasında açıklanamayan infertilite \%75.1 iken, varikosel \%12.6 ve üriner enfeksiyonlar ise $\% 66.6$ olarak etkili bulunmuştur (28).

\section{İnfertilitede Tedavi Yaklaşımı ve Yardımcı}

\section{Üreme Teknikleri}

İnfertilite tedavisi çiftlerin infertilite tanısı aldığında, tedaviye başlama kararı, tedavinin başarısız sonuçlanmasına verilen tepki, bu sürecin nasıl ilişkiye yansıdığı ve tedaviye yeniden karar verildiğinde tekrar yapılan denemeler tedavi sürecini belirlemektedir. $\mathrm{Bu}$ süreç basit bir tıbbı müdahale gibi görünse de derine inildiğinde tedavi aşamaları çifti çok yönlü etkilemektedir (29). İnfertilite tedavisi duygusal ve fiziksel zorluklara karşı çiftlerin aktif katılımını da gerektiren bir süreçtir. Tedavi süreci yoğun rutin ve cerrahi işlemlerin yanı sıra çiftlerin sağlık çalışanları ile sürekli iletişimde olmalarını gereken bir dönemdir (30).

İnfertilite tedavisinde öncelikli yaklaşım infertiliteye neden olan temel sorunun ortadan kaldırılmasıdır. $\mathrm{Bu}$ bakımdan stresli yaşam, uykusuzluk, beslenme bozukluğu, obezite, kullandığı ilaçlar, sigara ve alkol tüketimi gibi 
infertiliteye neden olan sorunlara yönelik danışmanlık verilmeli ve yaşam şekli değişikliği sağlanmalıdır $(31,32)$. Aynı zamanda bu basamak tedavi yaklaşımında infertiliteye neden olan sağlık sorununun tedavi edilmesi önem taşımaktadır. Mevcut sorun ovulasyon sürecine ait ise öncelikle ovulasyonun sağlanması önem taşımaktadır. $\mathrm{Bu}$ süreçte medikal ve cerrahi tedavi yöntemlerine başvurulmaktadır. Literatürde tıbbi ve cerrahi tedavi ile infertiliteye neden olan sorunların \%8590’’nın çözüldüğü belirtilmektedir (26,33). İnfertilite tedavisinde ikinci basamak yaklaşım ise Yardımcı Üreme Tekniklerinin (YÜT) kullanılmasıdır (26). YÜT spontan olarak gebe kalamayan çiftlerin, gebe kalmaları amacıyla yapılan tüm tedavi işlemlerini kapsamaktadır (34). Günümüzdeki uygulamada kullanılmakta olan en yaygın YÜT yaklaşımları intrauterin inseminasyon (IUI), in-vitro fertilizasyon (IVF) ve embriyo transferi (ET) ve intrasitoplazmik sperm injeksiyonudur (ICSI) (35). IUI yöntemi, cinsel ilişski dışında erkekten elde edilen spermlerin kadının ovulasyon periyodunda kadın üreme sistemi içerisine bırakma işlemi olarak tanımlanmaktadır (36). Bir diğer YÜT olan IVF ve ET, bir laboratuvar ortamında erkeğe ait sperm hücresi ile kadına ait matür ovumun fertilize edilmesi ve oluşan embriyonun uterusa transfer edilmesidir (34). ICSI ise önemli derecede erkek faktörünün bulunduğu veya nedeni açılanamamış infertilite durumunda direk ovum içerisine özel işlemlerden geçirilmiş sperm hücresinin mikroenjeksiyonudur (34).

\section{İnfertilite ve Uygulanan Tedavilerin Çiftler Üzerine Etkisi}

Üreme potansiyeli konusunda karşılaşılan sorunlar özellikle infertil çiftleri olumsuz yönde etkilemekle beraber, ani ve beklenmedik bir yaşam krizi olarak yaşanabilmektedir. Aynı zamanda infertilite tedavi süreçleri çiftler için uzun bir süreye yayılan, stres oluşturan ve uyum mekanizmalarını zorlayıcı bir olay olmaktadır (19,37). Babore'nın (38), erkek ve kadınların infertiliteye yönelik yaklaşımlarının araştırıldığı çalışmada, infertil kadınların erkeklere oranla ruhsal yönden daha fazla yoğun duygular yaşadığı belirlenmiştir. Hasanpoor-Azghady ve ark. (39) yaptığı araştırmada, infertil kadınların anksiyete, yorgunluk, çaresizlik, depresyon, endişe ve umutsuzluk duygularını fertil kadınlara göre daha yoğun yaşadıkları saptanmıştır. Yapılan bir başka araştırmada, infertil kadınların \%20'sınin yüksek düzeyde psikolojik stres yaşadıkları 
belirlenmiştir (37). Anokye ve ark.'nın (40) çalışmasında infertilite yaşayan çiftlerde umutsuzluk, damgalanma ve sosyal izolasyonun diğer fertil çiftlere göre daha fazla yaşandı ̆̆ saptanmıştır. İnfertil kadınların yaşadıkları duyguların incelendiği diğer bir çalışmada, infertilite sorunu yaşayan kadınlar kendilerini dışlanmış hissettiklerini ve çocuk sahibi olduklarında toplum tarafindan kabul edileceklerini düşündüklerini ifade etmişlerdir. Bununla birlikte aynı çalışmaya katılan kadınlar cinselliğin görev olarak algılanmasından dolayı kendilerini çekici bulmadıklarını belirtmişlerdir $(8,19)$. Shindel ve ark.'nın $(41)$, infertil çiftlerle ilgili yaptıkları çalışmada infertil erkeklerde cinsel işlev sorunlarının ve buna bağlı depresyonun daha fazla görüldüğü belirlenmiştir.

Aynı zamanda infertilteye yönelik uygulanan tedaviler çiftler için psikolojik yönden zorlayıcı, duygusal yönden oldukça stresli, ekonomik anlamda pahalı olmakla birlikte eş ilişkilerini de olumsuz etkileyebilen bir kriz durumudur $(21,42)$. İnfertil kadınlar bu süreçte, tanı ve tedavi işlemleri, bu tedavilerin uzun sürmesi ve ağrılı olması, tedavinin başarısız olması gibi nedenlerle kontrol kaybı, suçluluk, kadınlık algısında ve benlik algısında bozulma, yüksek düzeyde anksiyete ve depresyon yaşayabilmektedir $(4,5)$.

Bunun yanı sıra YÜT'de yaşanan başarısızlık sonrası kadınlar, cinsel istek ve ilgi düzeylerinin azaldığını bildirmişlerdir $(18,30)$. Ozan ve Okumuş’un (43) yaptıkları nitel bir çalışmada infertil kadınlar sosyal çevresindeki kişilerden, tedaviye başladıklarını gizlediklerini ve tedavi sürecinin nasıl sürdügü hakkındaki sorulara cevap vermek istemediklerini belirtmişlerdir. Aynı zamanda literatürde YÜT ile gebe kalan annelerde, intrauterin dönemde bebeklerinde sağlık sorunlarının gelişebileceğine yönelik kaygılarının doğal yol ile gebe kalan kadınlara göre daha yüksek olduğu belirtilmektedir (29).

\section{Dünyada ve Ülkemizde İnfertilite}

\section{Hemşireliğinin Gelişimi}

İnfertilite hemşireliği ilk kez Amerikan Hemşireler Birliği tarafından 1985 yılında tanımlanmıştır. 1987 yılında ise infertilite hemşirelerinin rollerinin tanımlanması ve bakım standartlarının oluşturulması amacıyla "Royal College of Nursing Fertilite Hemşireleri Grubu" kurulmuştur. Böylelikle grubun yapmış olduğu çalışmalar doğrultusunda infertilite hemşireliğinin standartları belirlenmiştir $(44,45)$. Aynı zamanda Özel İlgi 
Grubu (The Nurses Special Interest Group) 1990 yılında Avusturalya'da infertilite hemşireliğini ve standartlarını tanımlamak amacıyla kurulmuştur. $\mathrm{Bu}$ grup Avusturalya Fertilite Topluluğu (The Fertility Society of Australia) ad1 altında Avusturalya Fertilite Hemşireleri (Fertility Nurses Australia - FNA) adını alarak faaliyetlerini sürdürmektedir $(45,46)$.

Japon İnfertilite Hemşireliği A $\breve{1}$ (Japan Infertility Nursing Network - JINN) ise 1999 y1lında Japonya'da kurulmuş olup, infertilite hemşireliği sertifikasyon programlarının yürütülmesini organize etmektedir (47). İnfertilite alanında en az üç yıl çalışan hemşireler uzman infertilite hemşireliği sertifika programına başvurabilmekte ve yapilan sinavlarin ardindan sertifikalandirılmaktadır (44).

Ülkemizde ise infertilite hemşireliğine yönelik kurs ve toplantı faaliyetlerini yürüten iki dernek bulunmaktadır. $\mathrm{Bu}$ derneklerden "İstanbul İnfertilite Hemşirelerin Grubu” 2006 yılında kurulmuş olup, 2008 yılında "Üreme Sağlığı ve İnfertilite Hemşireliği Derneği” olarak ismi değiştirilmiştir. "İnfertilite Hemşireliği Derneği”" ise 2008 yılında Ege Üniversitesi Tüp Bebek merkezinde çalışan hemşireler tarafından kurulmuştur (48).

İnfertilite hemşireliği çalışılan yer ve ilgilenilen hastaların özel olması nedeniyle özellikli donanım, bilgi ve uygulaması olan bir dal hemşireliğidir. Ülkemizde halen infertilite hemşiresi görev, yetki ve sorumluluklarına yönelik yasal bir düzenleme bulunmamaktadır $(44,48)$. Bu bakımdan bu alanda çalışan hemşirelerin klinik uygulamalarının nasıl tanımlanacağı belli olmadığı için hemşireler arasında klinik bilgi, beceri ve eğitim düzeyleri yönünden farklılıklar olmaktadır. Ancak, infertilite kliniğinde çalışan hemşirelere infertilite hemşireliği hakkında lisansüstü ve doktora derslerinin verilmesi, infertilite konusunda hemşirelik tezlerinin yürütülmesi, kongre ve kursların yapılması hemşirelere ayrıcalık kazandırmaktadır.

\section{İnfertilite Hemşiresinin Rolü}

İnfertilite süreci profesyonel bir ekip işidir. $\mathrm{Bu}$ ekibin içinde hemşireler hasta ile yakından ilgilendikleri için görev, sorumlulukları ve rolleri önemlidir. İnfertilite de hemşirelik poliklinikle başlayan ve ameliyathaneye kadar devam eden infertil çiftlerin içinde bulundukları sosyal ve psikolojik durumu göz önünde bulunduran bir 
süreçtir. Uygulanan hemşirelik bakımının genel olarak amacı, çiftin psikolojik, sosyal ve fiziksel durumunun değerlendirilmesi, sorun ve ihtiyaçların belirlenip buna yönelik uygun bakımın oluşturulmasıdır $(2,21,45)$. İnfertil çiftlerle iletişim sırasında güler yüzlü, yumuşak bir ses tonuyla ve hoşgörülü davranmak önemlidir. Tedaviye gelen hastaların pek çoğu evlilik süresi uzun olan ve yıllarca sorunlarının çözüme ulaşması için tedavi arayan, ümitsiz, psikolojik ve ekonomik açıdan bitkin olan çiftler oluşturmaktadır $(18,29)$. Tedavi boyunca infertil çiftlerin yapılacak işlemlere fiziksel ve duygusal açıdan hazırlanması, teknik ve tıbbı bilgilerin anlaşılması ve beklentilerin gerçekçi olmasının sağlanmasında infertilite hemşiresinin rolü oldukça önemlidir. İnfertilite nedeninin öğrenilmesi sırasında çiftlerin benlik saygısı ve imajına etki edebilecek fiziksel muayene ve laboratuvar testler gerektirir. Hemşire bu aşamada çifti beraber değerlendirip, duygularını ifade etmelerini sağlamalıdır. Değerlendirme süresince hemşire çiftlerin uyum ve motivasyon düzeyinin etkileyen etmenler açısından gözlem yapmalı ve desteklemelidir. İnfertilite değerlendirmesinde yapılacak olan testlerin uygulama şekli, neden yapıldığ 1 ve testten önce ve sonra neler yapılacağ konularında infertil çiftler hemşire tarafindan bilgilendirmeli ve işlem boyunca desteklenmelidir $(9,18,49)$. Ekip içerisinde inferilite hemşiresinin tıbbı bakım rolünün yanı sıra değişen ve gelişen rolleri eğitmen/danışman, hasta hakları savunucusu, kalite güvencesi, psikolojik destek, yönetici, koordinatör, destekleyici, araştırmacı rollerini üstlenmişlerdir $(45,49)$. İnfertil çiftle en sık karşılaşan sağlık profesyoneli olması sebebi ile tanı ve tedavi sürecinde yaşam deneyimlerinin paylaşılması, eğitim ve danışmanlık yapılması noktasında hemşirelere anahtar roller düşmektedir (49). İnfertilite yaşama süresinde ortaya çıkan psikolojik etkilerin süresi uzadıkça yaşanılan sorunların önemli ölçüde arttığı bilinmektedir. İnfertilitede tanı ve tedavi süresince çiftler stres, duygusal yönden baskı ve panik durumu hissetmektedirler. İnfertilite hemşiresi bu aşamada çiftler için bilgi kaynağı olmakla beraber yaşanılan stresi azaltmak için etkin rol üstlenmektedir (45). Hemşirenin infertilite sorunu olan eşlerin soruna yönelik uygun bakıma yönlendirme, infertilite tedavisi süresince destekleyici ve danışmanlık rolü son derece önem arz etmektedir $(18,29)$. İnfertil çiftlerin tanı ve tedavi süresince infertilite ve yardımcı üreme tekniklerinin oluşturduğu 
problemleri bilerek, hemşirelik yaklaşımında bulunmak oldukça önem arz etmektedir $(9,18)$. İnfertil çiftlere tanı ve tedavide yapılan tüm işlem aşamalarında hemşire hastayı hazırlamak ve işlem sonrasında gerçekleştirdiği tüm izlem ve uygulamaları uygulayıc1/klinisyen rolünü yansitmaktadir $(21,45)$.

Hemşirelik uygulamalarında yeni gelişmeleri en doğru şekilde yansıtabilmek için infertilite hemşiresi araştırma planlamalı ve araştırma sonuçların kullanabilmektedir. Uygulanan işlevler sırasında hemşire profesyonel sorumluluk ve saygınlık ile ekibin diğer çalışanlarıyla uyum halinde çalışarak modern hemşirelik uygulamalarını göstermektedir $(9,45,49)$.

İnfertilitede tedavi, tanı ve erken gebelik sürecinde infertilite hemşireliği kanıta dayalı bilgi ve deneyimlerini kullanarak infertil çiftlere bütüncül ve sevecen yaklaşmayı gerektiren özel etkin bir alan olmaktadır. Kanıta dayalı uygulamalar, en iyi bakımın hastaya nasıl verebileceğini gösterir. Aynı zamanda sürekli araştırma yapıp eğitim almayı gerektirmektedir. Kanıta dayalı uygulamaların olması uygulanan bakımın kalitesini ve bakımın sonuçlarını iyileştirmekte ve hasta bakım sonuçlarında önemli ölçüde fark yaratmaktadır.
Böylelikle uygulanan bakımın standardize olmakta ve hemşirenin iş doyumu arttırmaktadır $(50,51)$. Kanıta dayalı uygulamaları gerçekleştirmek için hemşirenin bazı becerilere sahip olması gerekmektedir. $\mathrm{Bu}$ beceriler; soru sorma, sorulan soruya yanıt arama, kanıtı değerlendirme ve sonuçları uygulamadır. Hemşirenin hasta bakımında yaşamsal ve kritik yönde karar alma sürecinde kilit rolü bulunmaktadır $(51,52)$.

\section{SONUÇ}

İnfertilite sadece toplumsal bir hastalık olmayıp çiftleri ve özellikle kadınları biyolojik, fiziksel ve psikososyal yönden olumsuz etkileyen bir durumdur. Aynı zamanda infertilteye yönelik uygulanan tedaviler çiftler için psikolojik yönden zorlayıc1, duygusal yönden oldukça stresli, ekonomik anlamda pahalı olmakla birlikte eş ilişskilerini de olumsuz etkileyebilen bir kriz durumudur. İnfertilite kliniğinde çalışan hemşireler infertilite tedavisi süresince çiftlerle birebir iletişimde oldukları için yaşanabilecek sorunları erken dönemde belirlemesi ve uygun hemşirelik yaklaşımını planlayarak çiftlere destek olması önem taşımaktadır. İnfertilite hemşiresinin verebileceği danışmalık, eğitim ve sosyal destek ile kriz anında oluşabilecek olumsuz etkiler 
azaltılabilmektedir. $\mathrm{Bu}$ bakımdan Ülkemizde

infertilite hemşirelerinin görev tanımlarının

yapılarak, bu alanda açılan sertifika ve lisansüstü

programlarla uzmanlaşmaya gidilmesinin oldukça

önemli olduğu düşünülmektedir. Bunun yanı sıra

infertilite hemşireliğinde bakım standartlarının

oluşturulmasında bu alanda daha fazla kanıt temelli

çalışmalarının yapılmasının gerektiği

düşünülmektedir.

\section{KAYNAKÇA}

1. Cloonan YK, Holt VL, Goldberg J. Male factor infertility: A twin study. Perinatal Epidemiology. 2007; 21(3):229-34.

2. Allan H, Mounce G. Managing infertility in primary care. Practice Nursing. 2015; 26(9):440-3.

3. World Health Organization [Internet]. Mother or nothing: The agony of infertility. 2010 [cited 2018 Jan 16 ]. Available from: https://www.who.int/reproductivehealth/publications/infertility/bulleti n_88_12/en/

4. Sezgin H, Hocaoğlu Ç. İnfertilitenin psikiyatrik yönü. Psikiyatride Güncel Yaklaşımlar. 2014; 6(2):165-84.

5. Kırca N, Pasinlioğlu T. İnfertilite tedavisinde karşılaşılan psikososyal sorunlar. Psikiyatride Güncel Yaklaşımlar. 2013; 5(2):162-78.

6. Seymenler, S, Siyez DM, İnfertilite psikolojik danışmanlığı. Psikiyatride Güncel Yaklaşımlar. 2018; 10(2):176-87.

7. Ünal S, Kargın M, Akyüz A. İnfertil kadınları psikolojik olarak etkileyen faktörler. TAF Preventive Medicine Bulletin. 2010; 9(5):4816.

8. Bayley TM, Slade P, Lashen H. Relationships between attachment, appraisal, coping and adjustment in men and women experiencing infertility concerns. Human Reproduction. 2009; 24(11):2827-37

9. Aşçı Ö, Beji KN. İnfertilite danışmanlığı. İstanbul Üniversitesi Florence Nigthingale Hemşirelik Dergisi. 2012; 20(2):154-9.

10. Petraglia F, Serour GI, Chapron C. The changing prevalence of infertility. International Journal of Gynecology Obstetrics. 2013; 123:4-8.

11. World Health Organization [Internet]. Infertility definitions and terminology. 2019 [cited 2020 Sep 15]. Available from: https://www.who.int/reproductivehealth/topics/infertility/multipledefinitions/en/

12. Denson V. Diagnosis and management of infertility. The Journal for Nurse Practitioners. 2006; 1:380-6.

13. Araoye MO. Epidemiology of infertility: social problems of the infertile couples. West African Journal of Medicine. 2003; 22(2):1906.

14. Mascarenhas NM, Flaxman RS, Boerma T,Vanderpoel S, Steven AG. National, regional and global trends in infertility prevalence since 1990: a systematic analysis of 277 health surveys. PLoS Medicine. 2012; 9(12):1-2.

15. Datta J, Palmer MJ, Tanton C, Gibson LJ, Jones KG, Macdowall W, et al. Prevalence of infertility and help seeking among 15000 women and men. Human Reproduction. 2016; 31(9):2108-18.

16. Şimşek S. Sociocultural effects of infertility. Eurasian Academy of Sciences Social Sciences Journal. 2017; 12:55-6.
17. Türkiye Nüfus ve Sağlık Araştırması [Internet]. Hacettepe Üniversitesi Nüfus Etütleri Enstitüsü 2008 Raporu. 2012 [cited 2018 Jul 20]. Available from: http://www.hips.hacettepe.edu.tr/tnsa2008/data/TNSA-2008_anaRapor-tr.pdf

18. Yumru AE, Öndeş B. İnfertil çifte yaklaşım ve in vitro fertilizasyona doğru hasta seçimi. Journal of Academic Research in Medicine. 2011; 1(2):57-60.

19. Taşçı E, Bolsoy N, Kavlak O, Yücesoy F. İnfertil kadınlarda evlilik uyumu. Türk Jinekoloji ve Obstetrik Derneği Dergisi. 2008; 5 (2):10510.

20. Speroff L, Fritz MA. Erkek infertilitesi. Günalp S. Çeviri Editörü. Klinik jinekolojik endokrinoloji ve infertilite. 8. baskı. İstanbul: Güneş Tip Kitap Evleri; 2013. s. 1249-1292.

21. Eryılmaz HY, Ekşi Z, Ertuğrul EG. İnfertilite tanı yöntemleri ve hemşirenin rolü. In: Beji NK, ed. İnfertilite hemşireliği. İstanbul: Acar Basım; 2009. s. 49-66.

22. Enilo OW, Adetola AA, Abayomi T. A review of female Infertility; important etiological factors and management. Journal of Microbiology and Biotechnology Research. 2012; 1(2):134-7.

23. Bolumar F, Olsen J, Rebagliato M, et al. Body mass index and delayed conception: a european multicenter study on infertility and subfecundity. American Journal of Epidemiology. 2000; 151(11):107279.

24. Anderson K, Niesenblat V, Norman R: Lifestyle factors in people seeking infertility treatment - a review. Australian and New Zealand Journal of Obstetrics and Gynaecology. 2010; 50(1):8-20

25. Homan GF, Davies M, Norman R. The impact of lifestyle factors on reproductive performance in the general population and those undergoing infertility treatment: a review. Human Reproduction Update 2007; 13(3):209-23.

26. Duvan C, Şatıroğlu H, Berker B, Çetinkaya E, Kahraman K. Yardımla üreme tekniklerinde implantasyon ve gebelik oranlarını etkileyen faktörler. Türkiye Klinikleri Jinekoloji Obstetrik. 2003; 13:466-76.

27. Bidzan M, Podolska M, Bidzan L, Smutek, J. Personality traits and the feeling of loneliness of women treated for infertility. Ginekologia Polska. 2011; 82(7):508-13.

28. Famurewa AC, Ugwuja EI. Association of blood and seminal plasma cadmium and lead levels with semen quality in non-occupationally exposed infertile men in abakaliki, south east Nigeria. Journal of Family and Reproductive Health. 2017; 11(2):97-103.

29. Koç E, Kızılkaya Beji N. Başarılı infertilite tedavisi sonrası gebelerin yaşadığı problemler ve danışmanlık. Düzce Üniversitesi Sağlık Bilimleri Enstitüsü Dergisi. 2016; 6:201-6.

30. Güleç G, Hassa H, Yalçın EG, Yenilmez Ç. Tedaviye başvuran infertil çiftlerde, infertilitenin cinsel işlev ve çift uyumuna etkisinin değerlendirilmesi. Türk Psikiyatri Dergisi. 2011; 22(3):166-76.

31. Koçak DY, Büyükkayacı Duman N. İnfertilitenin psikolojik etkileri ve hemşirelik yaklaşımı. Türkiye Klinikleri. 2016; 2(3):7-13.

32. Amanak K, Karaöz B, Sevil Ü. Modern yaşamın infertilite üzerine etkisi. TAF Preventive Medicine Bulletin. 2014; 13(4):345-50.

33. Taşkın L. Doğum ve Kadın Sağlığı Hemşireliği. 8. baskı. Ankara: Sistem Ofset Matbaacilık; 2007. s. 255-264, 516-520.

34. Hjelmstedt A, Widström AM, Collins A. Psychological correlates of prenatal attachment in women who conceived after in vitro fertilization and women conceived naturally. BIRTH. 2006; 33(4):303-10

35. Erdem K, Ejder Apay S. A sectional study: the relationship between perceived social support and depression in Turkish infertile women. International Journal of Fertility and Sterility. 2014; 8:303-14.

36. Merviel P, Heraud MH, Grenier N, Lourdel E, Sanguinet P, Copin H. Predictive factors for pregnancy after intrauterine insemination (IUI): an analysis of 1038 cycles and a review of the literature. Fertility and Sterility. 2010; 93(1):79-88.

37. Gibson FL, Ungerer JA, Tennant CC, Saunders DM. Parental adjustment and attidudes to parenting after in vitro fertilization. Fertility and Sterility. 2000; 73(3):565-74.

38. Babore, A, Stuppia, L, Trumello, C, Candelori, C, Antonucci, I. Male factor infertility and lack of openness about infertility as risk factors for depressive symptoms in males undergoing assisted reproductive technology treatment in Italy. Fertility and Sterility. 2017; 107(4):1041-7.

39. Hasanpoor-Azghdy SB, Simbar M, Vedadhir A. The emotionalpsychological consequences of infertility among infertile women seeking treatment: results of a qualitative study. Iranian Journal of Reproductive Medicine. 2014; 12(2):131.

40. Anokye, R, Acheampong, E, Mprah WK, Ope JO, Barivure TN. Psychosocial effects of infertility among couples attending st. 
Michael's Hospital, Jachie-Pramso in the Ashanti Region of Ghana. BMC Research Notes. 2017; 10(1):690-4.

41. Shindel AW, Nelson CJ, Naughton CK, Mulhall JP. Premature ejaculation in infertile couples: prevalence and correlates. The Journal of Sexual Medicine. 2008; 5:485-91.

42. Haliloğlu S, Sağlam ZA, Toprak D. İnfertilite polikliniğine başvuran kadın hastaların sosyodemografik özelliklerinin değerlendirilmesi. Smyrna Tip Dergisi. 2013; 15:1-7.

43. Durgun Ozan Y, Okumuș H. Tedavi sonucu başarısız olan infertil kadınların Watson'ın insan bakım kuramına göre hemşirelik bakımı. Anadolu Hemşirelik ve Sağlık Bilimleri Dergisi. 2013; 16(3):190-8

44. Royal College of Nursing Publications [Internet]. 2012 [cited 2015 Dec 30]. Available from: http://www.rcn.org.uk/publications.

45. Dinc A, Beji NK. Yardımcı üreme teknikleri ve hemşirelik yaklaşımları. In: Beji NK, ed. İnfertilite sorunu, yardımcı üreme teknikleri ve hemşirelik yaklaşımı; İstanbul. Emek Matbaacılık; 2001. s. $75-92$

46. The Fertility Society of Australia [Internet]. 2012 [cited 2014 Mar 20]. Available from: http://www.fertilitysociety.com.au/login/fna

47. Role of the Fertility Nurse in Japan [Internet]. 2012 [cited 2015 Mar 20]. Available from: http://www.kango-net.jp/project/06/ppt/06.ppt

48. Beji N. İstanbul infertilite hemşireleri grubu 2007-2008 yll faaliyetleri. Ulusal Üreme Endokrinolojisi ve İnfertilite Kongresi (TSRM 2008), İnfertilite Hemşireliği Kurs Notları. 2008; 3-10.

49. Payne D, Goedeke S. Holding together :caring for clients undergoing assisted reproductive technologies. Journal of Advanced Nursing. 2007; 60(6):645 -53.

50. Uçan Ö, Taşçı S, Ovayolu N. Eleştirel düşünme ve hemşirelik. Fırat Sağlık Hizmetleri Dergisi. 2008; 3(7):17-25.

51. Küçükkaya GP. Psikiyatri hemşireliğinde kanıta dayalı uygulama. Psikiyatri Hemşireliği Dergisi. 2010; 1(3):128-31.

52. Kocaman G. Hemşirelikte kanıta dayalı uygulama. Hemşirelikte Araştırma Geliştirme Dergisi. 2003; (2):61-7.

53. Perk H, Soyupek S, Oskay T. Erkek infertilitisine neden olan fiziksel ajanlar, ilaçlar ve toksinler. Androloji Bülteni. 2005; 23:305-10. 